\title{
ALLOGENICITY OF CRYOPRESERVED HUMAN FIBROBLASTS: CRYOPRESERVATION DOES NOT DOWNREGULATE THE ALLOGENICITY OF FIBROBLASTS MAKING UP THE MATRICES OF ALLOGRAFTS
}

Tomohiro Murakawa, MD

Jun Nakajima, MD

Minoru Ono, MD

Arata Murakami, MD

Yoshihiro Suematsu, MD

Shinichi Takamoto, MD
Background: Although cryopreserved tissue allografts are being widely used, long-term degeneration of implanted cryopreserved allografts has become a problem. Although immunologic rejection has been suggested to play a part in this degeneration, cryopreserved allografts are considered to be less immunogenic than fresh allografts.

Objective: We investigated the effect of cryopreservation on the allogenicity of the fibroblasts that make up the matrices of allografts.

Methods: Fibroblast cell strains obtained from surgically resected lung specimens were used. Allogenicity-related antigens expressed on the cell surface (human leukocyte antigen 1, human leukocyte antigen 2, and intercellular adhesion molecule 1), stimulation indices during 1-way mixed lymphocytefibroblast cell culture, and proliferation indices of freshly passaged fibroblasts and cryopreserved fibroblasts stored for 1, 4, and 24 weeks were examined. Flow cytometric analysis with monoclonal antibodies was used to test for cell surface antigens, and a colorimetric methyl-thiazol-diphenyltetrazolium assay was used to assess stimulation indices and fibroblast proliferation indices. The effect of exogenous interferon- $\gamma$ on the degree of expression of human leukocyte antigen 1, human leukocyte antigen 2, and intercellular adhesion molecule 1 was examined simultaneously.

Results: The proliferation indices of fibroblasts were well maintained by cryopreservation. Expression of human leukocyte antigen 1, human leukocyte antigen 2 , and intercellular adhesion molecule 1 by fibroblasts was significantly upregulated by interferon- $\gamma$, and cryopreservation did not downregulate this expression.

Conclusion: Our study suggests that although the fibroblast cell component may be beneficial in restoring allograft function properties initially, it may render the implanted allograft more immunogenic, ultimately resulting in greater rejection and inflammatory responses by the host and, in turn, degeneration of the graft. (J Thorac Cardiovasc Surg 2000;120:712-9)
From the Department of Cardiothoracic Surgery, Faculty of Medicine, University of Tokyo, Tokyo, Japan.

Received for publication Feb 11, 2000; revisions requested March 14, 2000; revisions received April 26, 2000; accepted for publication May 25, 2000.

Address for reprints: Tomohiro Murakawa, MD, Department of Cardiothoracic Surgery, Faculty of Medicine, University of Tokyo, 7-3-1 Hongo, Bunkyo-ku, Tokyo 113-8655, Japan (Email: [1] MURAKAWA-THO@h.u-tokyo.ac.jp; [2] tymurakawa@aol.com.

Copyright (C) 2000 by The American Association for Thoracic Surgery

$0022-5223 / 2000 \$ 12.00+0 \quad \mathbf{1 2 / 1 / 1 0 9 2 3 8}$

doi:10.1067/mtc.2000.109238
Cryopreserved tissue allografts are thought to be less Uimmunogenic than fresh allografts, ${ }^{1-3}$ but some reports have suggested that graft degeneration may be caused by immunologic rejection of the donor graft. ${ }^{4,5}$ The current procedure for tissue allograft cryopreservation is focused on preserving the fibroblasts that make up the matrices of allografts to increase graft durability $^{6,7}$; these cells are viable in situ even after cryopreservation. In this study we focused on the allogenicity of fibroblasts and investigated the effect of cryopreservation on them. The allogenicity-related antigens expressed on the surface of the cells were 
assayed by using flow cytometry, and we simultaneously examined the effect of exogenous interferon- $\gamma$ (IFN- $\gamma$ ), which promotes the expression of major histocompatibility complex antigens. Stimulation indices (SIs) were also examined by 1-way mixed lymphocyte-fibroblast cell cultures (MLFCs), and the proliferation indices (PIs) of fresh and cryopreserved fibroblasts were examined by a colorimetric methylthiazol-diphenyl-tetrazolium (MTT) assay.

\section{Methods}

Monoclonal antibodies. The monoclonal antibodies (mAbs) used in this study were as follows: antifibroblast antigen antibody (Ab-1: \#CP28; Calbiochem, Cambridge, Mass), fluorescein isothiocyanate (FITC)-conjugated anticytokeratin antibody (CAM 5.2: \#347653; Becton-Dickinson Immunocytometry System, San Jose, Calif), FITC-conjugated anti-HLA-1 antibody (\#09HHLA01E; Sileus, Hawthorn, Australia), phycoerythrin-conjugated anti-HLA-2 antibody (\#347367, Becton-Dickinson Immunocytometry System), and anti-intercellular adhesion molecule (ICAM) 1 (CD54) antibody (M7063; DAKO, Carpinteria, Calif). FITC-conjugated mouse anti-rat IgG mAb (F0479, DAKO) was used as the second antibody for indirect immunofluorescence.

Preparation of the fibroblast strains and lymphocytes. After the patients' informed consent had been obtained, fibroblasts were isolated from surgically resected human lung tissue by means of enzymatic digestion (120 minutes at room temperature) with $0.25 \%$ trypsin and $1 \mathrm{mmol} / \mathrm{L}$ ethylenediamine tetraacetic acid (EDTA; \#25200-056; Gibco BRL, Life Technologies, Inc, Rockville, Md) and cultured at $37^{\circ} \mathrm{C}$ in a 75- $\mathrm{cm}^{2}$ Tissue Culture Flask (\#3110-075; Iwaki Glass, Chiba, Japan) with Roswell Park Memorial Institute (RPMI) medium 1640 (\#31800-022, Gibco BRL) containing 15\% fetal bovine serum (\#26140-079, Gibco BRL) and 1\% penicillinstreptomycin (\#15140-122, Gibco BRL) in an incubator filled with $5 \%$ carbon dioxide. After 4 to 5 passages, the proliferated cells were identified as fibroblasts by means of flow cytometric analysis of cell surface antigens with antifibroblast antigen antibody, as described previously by Johnson and colleagues. ${ }^{8}$ BEAS-2B, a human airway epithelial cell line (American Type Culture Collection registration number: CRL-9609),,${ }^{9,10}$ and peripheral blood mononuclear cells (PBMCs) were used as controls for the flow cytometric analysis. The fibroblasts were used for further investigation. PBMCs were separated from the blood of a healthy volunteer by density centrifugation with Lymphoprep (\#1001967; Nycomed Pharma, Oslo, Norway).

Cryopreservation procedure. The fibroblasts were divided into 2 groups: a further-passaged group (fresh cells) and a cryopreserved group (cryopreserved cells). The fibroblasts in the cryopreserved group were conjugated in Medium 199 (\#21200-076, Gibco BRL) containing 20\% fetal bovine serum and 10\% dimethylsulfoxide (\#134-06; Nacalai Tesque Inc, Kyoto, Japan) and then frozen in a programmable freezer (Profreezer; NipponFreezer Co, Tokyo, Japan), as described elsewhere. ${ }^{9}$ In brief, the specimen was cooled from room temperature to $4^{\circ} \mathrm{C}$ at a rate of $3^{\circ} \mathrm{C} / \mathrm{min}$ and then maintained at $4^{\circ} \mathrm{C}$ for 5 minutes. It was then cooled at $1{ }^{\circ} \mathrm{C} / \mathrm{min}$ from $4^{\circ} \mathrm{C}$ to $-50^{\circ} \mathrm{C}$ and at $5^{\circ} \mathrm{C} / \mathrm{min}$ from $-50^{\circ} \mathrm{C}$ to $-80^{\circ} \mathrm{C}$. After the temperature of the specimen reached $-80^{\circ} \mathrm{C}$, it was preserved at $-130^{\circ} \mathrm{C}$ in the vapor phase of liquid nitrogen for 1,4 , and 24 weeks. The fibroblasts were then thawed rapidly to $37^{\circ} \mathrm{C}$. The passaged cells and the cryopreserved cells were incubated for 48 hours in RPMI-1640 medium containing $15 \%$ fetal bovine serum and $1 \%$ penicillin-streptomycin with and without IFN- $\gamma$ (\#13322-029, Gibco BRL; $100 \mathrm{ng} / \mathrm{ml}$ ), yielding the following 8 groups: fresh cells without IFN- $\gamma$; fresh cells with IFN- $\gamma$; 1 -week cryopreserved cells without IFN- $\gamma$; 1 -week cryopreserved cells with IFN- $\gamma$; 4-week cryopreserved cells without IFN- $\gamma$; 4-week cryopreserved cells with IFN- $\gamma$; 24 -week cryopreserved cells without IFN- $\gamma$; and 24 -week cryopreserved cells with IFN- $\gamma$. Fibroblasts of the 8 groups prepared were then submitted to flow cytometric analysis, and the freshly passaged cells and cryopreserved cells, namely the fresh cells without IFN- $\gamma$, the 1-week cryopreserved cells without IFN- $\gamma$, the 4-week cryopreserved cells without IFN- $\gamma$, and the 24 -week cryopreserved cells without IFN- $\gamma$, were investigated in regard to the following: (1) stimulation indices in 1-way mixed lymphocyte-fibroblast cell culture and (2) the proliferation indices of the cells.

Flow cytometric analysis. To identify fibroblasts, we examined the surface antigens of cultured proliferated cells by using flow cytometric analysis, with BEAS-2B and PBMCs as controls, and the surface HLA-1, HLA-2, and ICAM-1 molecules on the fibroblasts of the 8 groups prepared as described above were examined by flow cytometric analysis with a FACScalibur system (Becton-Dickinson Immunocytometry System). After incubation of $10^{5}$ cells for 15 minutes at room temperature in $100 \mu \mathrm{L}$ of phosphate-buffered saline solution (PBS) containing $10 \mu \mathrm{L}$ of each $\mathrm{mAb}$, the cells were washed and then incubated for 15 minutes at room temperature in $100 \mu \mathrm{L}$ of PBS containing the second antibody. After being washed, the cells were suspended in $300 \mu \mathrm{L}$ of PBS for flow cytometry, as reported previously. ${ }^{10}$ Each negative control specimen was conjugated in the second antibody without the mAb.

One-way MLFC. MLFCs were made up of $1 \times 10^{6} / \mathrm{mL}$ PBMCs and $1 \times 10^{5} / \mathrm{mL}$ fresh or cryopreserved fibroblasts from the fresh cells without IFN- $\gamma, 1$-week cryopreserved cells without IFN- $\gamma$, 4-week cryopreserved cells without IFN$\gamma$, and 24-week cryopreserved cells without IFN- $\gamma$ groups irradiated with $50 \mathrm{~Gy}$ and $50 \mu \mathrm{L}$ of complete medium (RPMI-1640 medium containing 15\% fetal bovine serum and $1 \%$ penicillin-streptomycin). Cells were counted by the dye exclusion method with $0.4 \%$ trypan blue (\#15250-012, Gibco BRL). The cells were cultured in a 96-well microplate (MicrotestIII Tissue Culture Plate; \#3072, Falcon, BectonDickinson) in triplicate. The MLFCs were incubated for 72 hours at $37^{\circ} \mathrm{C}$ in $5 \%$ carbon dioxide. After incubation, a colorimetric MTT assay (CellTiter, \#G4000; Promega, Madison, Wis) was performed to determine the degree of proliferation, as described elsewhere. ${ }^{10}$ In brief, $15 \mu \mathrm{L}$ of dye solution was added to each well followed by incubation for 4 hours under 


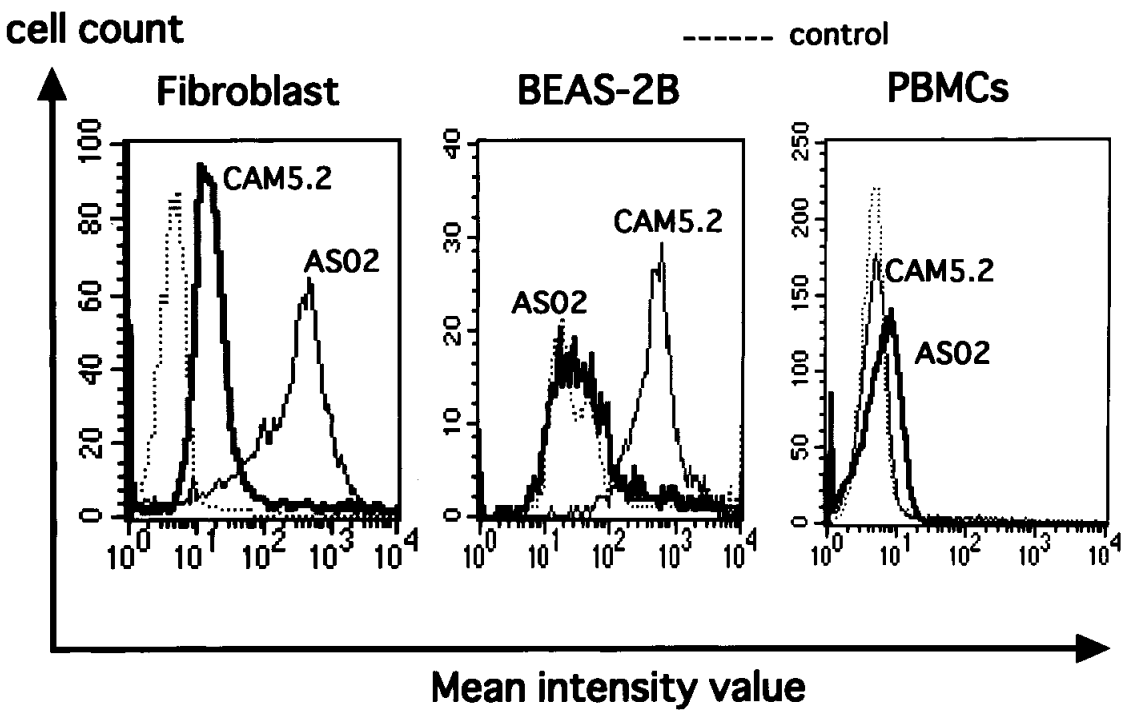

Fig 1. Histogram of flow cytometric analysis of isolated fibroblasts, BEAS-2B cells, and PBMCs. ASO2, Antifibroblast antigen; CAM5.2, anticytokeratin antibody.

carbon dioxide, and $100 \mu \mathrm{L}$ of stop solution was added to each well. The absorbance at a wavelength of $570 \mathrm{~nm}$, with a reference wavelength of $630 \mathrm{~nm}$, was measured with an enzyme-linked immunosorbent assay plate reader (MTP-32 Microplate Reader; Corona Electric, Ibaraki, Japan). The absorbance value was represented by a relative index, as follows: $\mathrm{SI}=($ sample absorbance $) /($ control absorbance $) \times 100$ $(\%)$, where the control absorbance value was that of the nonstimulated PBMCs.

Fibroblast proliferation assay. A colorimetric MTT assay (CellTiter) was performed to determine the degree of fibroblast proliferation. Cells were counted by using the dye exclusion method with $0.4 \%$ trypan blue. Fibroblast cultures were established with $1 \times 10^{6} / \mathrm{mL}$ fresh or cryopreserved cells from the fresh cells without IFN- $\gamma$, 1-week cryopreserved cells without IFN- $\gamma$, 4-week cryopreserved cells without IFN- $\gamma$, and 24-week cryopreserved cells without IFN- $\gamma$ groups. A $50-\mu \mathrm{L}$ volume of complete medium and $15 \mu \mathrm{L}$ of dye solution were added to each well in a 96-well microplate in triplicate, and it was incubated for 4 hours at $37^{\circ} \mathrm{C}$ in $5 \%$ carbon dioxide. At the end of the incubation period, $100 \mu \mathrm{L}$ of stop solution was added to each well, and the absorbance at a wavelength of $570 \mathrm{~nm}$ was measured with an enzymelinked immunosorbent assay plate reader, with a reference wavelength of $630 \mathrm{~nm}$. The absorbance value was reported as a relative index calculated as follows: $\mathrm{PI}=$ (sample absorbance $) /($ control absorbance $) \times 100(\%)$, where the control absorbance value was that of the culture medium without fibroblasts.

Statistical analysis. Data were analyzed with StatView J 5.0 (SAS Institute Inc, Cary, NC) on a Power Macintosh computer (Apple Inc, Cupertino, Calif). All data are expressed as means \pm SEM (6 fibroblast cell strains per group). Data were compared by 1-way or 2-way analysis of variance (ANOVA) and the Fisher post hoc multiple comparison technique.

\section{Results}

Identification of fibroblasts. Six proliferating cell strains were obtained from 11 lung tissue specimens. The surface antigens of the cells were analyzed by flow cytometry (Figs 1 and 2). They stained positive with antifibroblast antigen antibody but stained negative with anticytokeratin antibody and the second antibody. The cells stained positive with anti-HLA- 1 antibody but not with anti-HLA-2 antibody. BEAS-2B was positive with anticytokeratin antibody but negative with antifibroblast antigen antibody and the second antibody, and PBMCs were negative with antifibroblast antigen antibody, anticytokeratin antibody, and the second antibody. Antifibroblast antigen antibody (Ab-1) is a novel fibroblast-specific mAb (AS02) that can be used for detection and elimination of human fibroblasts. It shows no reactivity with keratinocytes, chondrocytes, smooth muscle cells, endothelial cells, or Langerhans cells in situ and does not bind to extracellular matrix proteins. ${ }^{11}$ The cell strains obtained were positive with mAb ASO2 and negative for anticytokeratin antibody, which stains epithelial-derived cells, such as airway epithelial cells. The cells expressed only HLA-1 and not HLA-2. Thus, the established cell strains were considered to be somatic fibroblasts and 


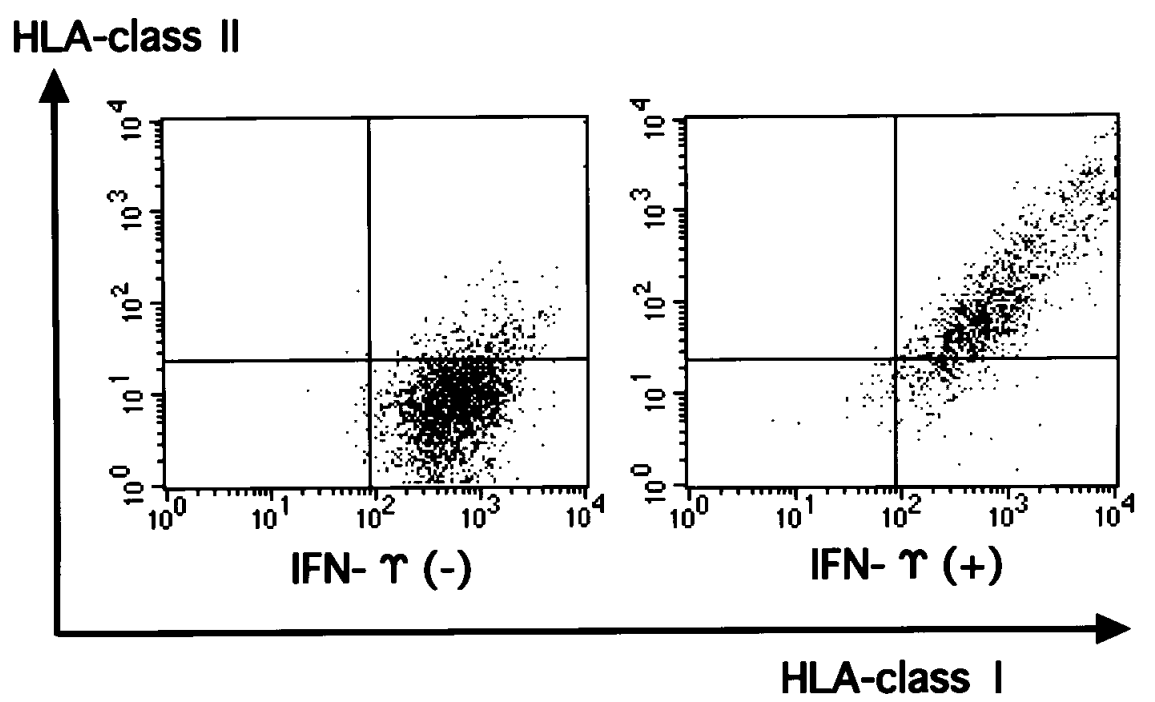

Fig 2. Two-color analysis of expression of HLA-1 and HLA-2 on the fibroblast cell surface. IFN- $\boldsymbol{\gamma}$-induced expression of HLA-2 is shown.

Table I. Mean intensity values for expression of HLA-1 on fibroblasts in the 8 groups

\begin{tabular}{lcccc}
\hline & $\begin{array}{c}\text { Fresh } \\
\text { cells }\end{array}$ & $\begin{array}{c}\text { One-week } \\
\text { cryopreserved cells }\end{array}$ & $\begin{array}{c}\text { Four-week } \\
\text { cryopreserved cells }\end{array}$ & $\begin{array}{c}\text { Twenty-four-week } \\
\text { cryopreserved cells }\end{array}$ \\
\hline Without IFN- $\gamma$ & & & $1878 \pm 277^{*}$ & $1813 \pm 348^{*}$ \\
$\quad \begin{array}{l}\text { Mean intensity value } \\
\text { Control value }\end{array}$ & $1731 \pm 384^{*}$ & $1908 \pm 308^{*}$ & $173 \pm 23$ & $104 \pm 14$ \\
With IFN- $\gamma$ & $80 \pm 19$ & $141 \pm 32$ & $4044 \pm 351^{*}$ & $4480 \pm 532^{*}$ \\
Mean intensity value & & $4679 \pm 507^{*}$ & $196 \pm 32$ & $105 \pm 8$ \\
Control value & $3528 \pm 571^{*}$ & $143 \pm 20$ & \\
\hline
\end{tabular}

All data are expressed as means \pm SEM

*A significant difference from the control value.

not antigen-presenting cells, such as vascular endothelial cells, airway epithelial cells, or dendritic cells.

Flow cytometric analysis of fibroblasts. The fibroblasts cultured without IFN- $\gamma$ expressed HLA-1 and ICAM-1 on their cell surface but not HLA-2 (Tables IIII). However, HLA-2 expression was induced on the cell surface of the fibroblasts by addition of exogenous IFN- $\gamma$ (Fig 2).

The effects of cryopreservation and IFN- $\gamma$ on expression of HLA-1, HLA-2, and ICAM-1 by fibroblasts were as follows.

$H L A-1$. The mean intensity values of HLA-1 as a measure of expression of the 8 groups and of their controls are shown in Table I. The overall differences among the 8 groups were determined by 1-way ANOVA, and the $P$ values were less than .0001 . Fibroblasts expressed HLA-1, and expression of HLA1 was not significantly changed by cryopreservation (fresh cells without IFN- $\gamma$ vs 1-week cryopreserved cells without IFN- $\gamma: P=.7687$; fresh cells without IFN$\gamma$ vs 4-week cryopreserved cells without IFN- $\gamma$ : $P=.8071$; fresh cells without IFN- $\gamma$ vs 24 -week cryopreserved cells without IFN- $\gamma: P=.8913$; fresh cells with IFN- $\gamma$ vs 1 -week cryopreserved cells with IFN- $\gamma$ : $P=.0611$; fresh cells with IFN- $\gamma$ vs 4-week cryopreserved cells with IFN- $\gamma: P=.3925$; fresh cells with IFN- $\gamma$ vs 24 -week cryopreserved cells with IFN- $\gamma: P=$ .1189) but was significantly enhanced by the addition of IFN- $\gamma$ (fresh cells without IFN- $\gamma$ vs fresh cells with IFN- $\gamma: P=.0046$; 1 -week cryopreserved cells without IFN- $\gamma$ vs 1 -week cryopreserved cells cells with IFN- $\gamma$ : $P<.0001$; 4-week cryopreserved cells without IFN- $\gamma$ vs 4-week cryopreserved cells with IFN- $\gamma$ : $P=.0008 ; 24$-week cryopreserved cells without IFN- $\gamma$ vs 24 -week cryopreserved cells with IFN- $\gamma$ : $P<.0001)$. Two-way ANOVA showed that the two factors (cryo- 
Table II. Mean intensity values for expression of HLA-2 on fibroblasts in the 8 groups

\begin{tabular}{lcccc}
\hline & $\begin{array}{c}\text { Fresh } \\
\text { cells }\end{array}$ & $\begin{array}{c}\text { One-week } \\
\text { cryopreserved cells }\end{array}$ & $\begin{array}{c}\text { Four-week } \\
\text { cryopreserved cells }\end{array}$ & $\begin{array}{c}\text { Twenty-four-week } \\
\text { cryopreserved cells }\end{array}$ \\
\hline Without IFN- $\gamma$ & & & & \\
$\quad$ Mean intensity value & $79 \pm 19$ & $74 \pm 7$ & $74 \pm 16$ & $53 \pm 7$ \\
$\quad$ Control value & $22 \pm 5$ & $36 \pm 5$ & $22 \pm 3$ & $18 \pm 3$ \\
With IFN- $\gamma$ & & & $1206 \pm 227^{*}$ & $2101 \pm 298^{*}$ \\
$\quad$ Mean intensity value & $1654 \pm 202^{*}$ & $2204 \pm 372^{*}$ & $29 \pm 3$ & $25 \pm 2$ \\
$\quad$ Control value & $33 \pm 7$ & $40 \pm 4$ & & \\
\hline
\end{tabular}

All data are expressed as means \pm SEM.

*A significant difference from the control value.

Table III. Mean intensity values for expression of ICAM-1 on fibroblasts in the 8 groups

\begin{tabular}{|c|c|c|c|c|}
\hline & $\begin{array}{c}\text { Fresh } \\
\text { cells }\end{array}$ & $\begin{array}{c}\text { One-week } \\
\text { cryopreserved cells }\end{array}$ & $\begin{array}{c}\text { Four-week } \\
\text { cryopreserved cells }\end{array}$ & $\begin{array}{l}\text { Tkwenty-four-week } \\
\text { cryopreserved cells }\end{array}$ \\
\hline \multicolumn{5}{|l|}{ Without IFN- $\gamma$} \\
\hline Mean intensity value & $545 \pm 90 *$ & $749 \pm 149 *$ & $774 \pm 115^{*}$ & $814 \pm 119 *$ \\
\hline Control value & $80 \pm 19$ & $141 \pm 32$ & $173 \pm 23$ & $104 \pm 14$ \\
\hline \multicolumn{5}{|l|}{ With IFN- $\gamma$} \\
\hline Mean intensity value & $3064 \pm 437^{*}$ & $3812 \pm 494^{*}$ & $2688 \pm 266^{*}$ & $2797 \pm 250^{*}$ \\
\hline Control value & $106 \pm 11$ & $143 \pm 20$ & $196 \pm 32$ & $105 \pm 8$ \\
\hline
\end{tabular}

All data are expressed as means \pm SEM.

*A significant difference from the control value.

preservation and the addition of IFN- $\gamma$ ) did not yield interaction terms $(P=.6337)$. Cryopreservation did not affect the expression of HLA-1 $(P=.4400)$, whereas addition of IFN- $\gamma$ affected it significantly $(P<.0001)$.

$H L A-2$. The mean intensity values of HLA-2 as a measure of expression of the 8 groups and of their controls are shown in Table II. The overall differences among the 8 groups were determined by 1-way ANOVA, and the $P$ values were less than .0001 . Fibroblasts did not express HLA-2 unless stimulated with IFN- $\gamma$, as shown in Table II (fresh cells without IFN- $\gamma$ vs control: $P=.7749$; 1 -week cryopreserved cells without IFN- $\gamma$ vs control: $P=.8510$; 4-week cryopreserved cells without IFN- $\gamma$ vs control: $P=.7926$; $24-$ week cryopreserved cells without IFN- $\gamma$ vs control: $P=$ .8628). However, stimulation with IFN- $\gamma$ significantly induced the expression of HLA-2 (fresh cells with IFN$\gamma$ vs control: $P<.0001 ; 1$-week cryopreserved cells with IFN- $\gamma$ vs control: $P<.0001 ; 4$-week cryopreserved cells with IFN- $\gamma$ vs control: $P<.0001 ; 24$-week cryopreserved cells with IFN- $\gamma$ vs control: $P<.0001$; fresh cells without IFN- $\gamma$ vs fresh cells with IFN- $\gamma: P<.0001 ; 1-$ week cryopreserved cells without IFN- $\gamma$ vs 1-week cryopreserved cells with IFN- $\gamma: P<.0001$; 4-week cryopreserved cells without IFN- $\gamma$ vs 4-week cryopreserved cells with IFN- $\gamma: P=.0003 ; 24$-week cryopreserved cells without IFN- $\gamma$ vs 24 -week cryopreserved cells with IFN- $\gamma: P<.0001)$. Cryopreservation did not alter the expression of HLA-2 (fresh cells without IFN- $\gamma$ vs 1 -week cryopreserved cells without IFN- $\gamma: P=.9849$; fresh cells without IFN- $\gamma$ vs 4-week cryopreserved cells without IFN- $\gamma: P=.9873$; fresh cells without IFN- $\gamma$ vs 24-week cryopreserved cells without IFN- $\gamma$ : $P=.9279$; fresh cells with IFN- $\gamma$ vs 1-week cryopreserved cells with IFN- $\gamma$ : $P=.0588$; fresh cells with IFN- $\gamma$ vs 4 -week cryopreserved cells with IFN- $\gamma: P=.1217$; fresh cells with IFN- $\gamma$ vs 24 -week cryopreserved cells with IFN- $\gamma$ : $P=.1219)$. Two-way ANOVA showed that the two factors (cryopreservation and the addition of IFN- $\gamma$ ) did not have interaction terms $(P=.0600)$. Cryopreservation did not affect the expression of HLA-2 $(P=.0692)$, but addition of IFN- $\gamma$ affected it significantly $(P<.0001)$.

ICAM-1. The mean intensity values of ICAM- 1 as a measure of expression of the 8 groups and of their controls are shown in Table III. The overall differences among the 8 groups were determined by 1-way ANOVA, and the $P$ values were less than .0001 . Fibroblasts expressed ICAM-1, and expression of ICAM-1 was not significantly changed by cryopreservation (fresh cells without IFN- $\gamma$ vs 1-week cryopreserved cells without IFN- $\gamma$ : $\mathrm{P}=.6087$; fresh cells without IFN- $\gamma$ vs 4 -week cryopreserved cells without IFN- $\gamma$ : 
$P=.5663$; fresh cells without IFN- $\gamma$ vs 24 -week cryopreserved cells without IFN- $\gamma: P=.5008$; fresh cells with IFN- $\gamma$ vs 1-week cryopreserved cells with IFN- $\gamma$ : $P=.0657$; fresh cells with IFN- $\gamma$ vs 4 -week cryopreserved cells with IFN- $\gamma: P=.3487$; fresh cells with IFN- $\gamma$ vs 24 -week cryopreserved cells with IFN- $\gamma: P=$ .5031 ), but it was significantly enhanced by the addition of IFN- $\gamma$ (fresh cells without IFN- $\gamma$ vs fresh cells with IFN- $\gamma$ : $P<.0001 ; 1$-week cryopreserved cells without IFN- $\gamma$ vs 1 -week cryopreserved cells with IFN- $\gamma$ : $P<.0001 ; 4$-week cryopreserved cells without IFN- $\gamma$ vs 4-week cryopreserved cells with IFN- $\gamma: P<.0001 ; 24-$ week cryopreserved cells without IFN- $\gamma$ vs 24 -week cryopreserved cells with IFN- $\gamma: P<.0001)$. Two-way ANOVA of the 2 factors (cryopreservation and the addition of IFN- $\gamma$ ) did not reveal interaction terms $(P=.1569)$. Cryopreservation did not affect the expression of ICAM-1 $(P=.1972)$, but addition of IFN- $\gamma$ affected it significantly $(P<.0001)$.

Lymphocyte proliferation assay by MLFCs. SIs were examined by MLFCs with a colorimetric MTT assay, as described above. The SI of each group was as follows: fresh cells without IFN- $\gamma$ group, $1.716 \pm$ 0.181 ; 1-week cryopreserved cells without IFN- $\gamma$ group, $1.382 \pm 0.058$; 4-week cryopreserved cells without IFN- $\gamma$ group, $1.567 \pm 0.104$; and 24 -week cryopreserved cells without IFN- $\gamma$ group, $1.430 \pm 0.101$. Oneway ANOVA showed no significant differences among the SIs of the 4 groups $(P=.225)$.

Fibroblast proliferation assay. PIs were examined by using a colorimetric MTT assay, as described above. The PIs of the groups were as follows: fresh cells without IFN- $\gamma$ group, $8.802 \pm 1.523$; 1 -week cryopreserved cells without IFN- $\gamma$ group, $6.863 \pm 1.653$; 4-week cryopreserved cells without IFN- $\gamma$ group, $7.575 \pm 1.612$; and 24week cryopreserved cells without IFN- $\gamma$ group, $6.948 \pm$ 1.476. One-way ANOVA showed no significant differences among the PIs of the 4 groups $(P=.8067)$.

\section{Comment}

Because human tissue allografts, exquisitely constructed of many cell components, are structurally far superior to prosthetic materials, and better methods of cryopreservation have been developed, if there is no immunologic rejection, cryopreserved human tissue allografts may be the ideal material for certain reconstructive procedures and can be available for clinical use at any time by establishing tissue banking system. ${ }^{7}$

Cryopreservation of allograft tissues should make them less immunogenic than fresh tissues. In actual fact, cryopreserved cardiac valve allografts have been transplanted without immunosuppressants in many clinical cases, ${ }^{7,12}$ as have cryopreserved tracheal allografts in animal models. ${ }^{1-3}$ However, graft degeneration has been observed in the late stage after allotransplantation of cryopreserved tissues, such as cardiac valves, and some authors have proposed that the degeneration is caused by immunologic graft rejection. ${ }^{4,5}$ However, whether cryopreservation downregulates the allogenicity of grafts is a matter of controversy. It is still unclear which component of the graft is mainly responsible for the late rejection phenomenon because the potent immunogenic components of allografts, such as vascular endothelial cells or airway epithelial cells, may be lost during the cryopreservation and thawing procedure ${ }^{2,13}$; cytokines induced by inflammation after surgical intervention may modify the immunologic reaction, and cryopreservation itself may modify the allogenicity of the cells making up the allograft. ${ }^{9}, 14,15$

We hypothesized that cryopreservation affects the allogenicity of cryopreserved cells making up allograft tissues, and we examined the effect of cryopreservation on the allogenicity of human vascular endothelial cells and human airway epithelial cells in vitro, as previously reported elsewhere. ${ }^{9,14,15}$ The in vitro experiments with a cell culture model revealed that the allogenicity-related antigens expressed on the cell surface can be modified by cryopreservation. In brief, expression of HLA-2 antigens on human vascular endothelial cells was upregulated by cryopreservation, ${ }^{14,15}$ but expression of HLA-2 antigens on the human-derived airway epithelial cell line BEAS-2B was downregulated. ${ }^{9}$

Current procedures for the cryopreservation of tissues are aimed at maintaining the fibroblasts within the matrix of the graft in good condition, thereby preserving the graft itself, because it has been suggested that the cells residing within the tissue matrix interstitium are important to post-transplantation durability. In this experiment we found that the fibroblast proliferation index was well maintained even after 24 weeks of cryopreservation, and this finding seems to support the current strategy.

Fibroblasts have been regarded as normal somatic cells that express only HLA-1 antigens on their surface and are far less potent immunologically. However, some reports have shown that fibroblasts may disappear after allotransplantation, suggesting rejection by the recipient. ${ }^{16,17}$ Our own results showed that fibroblasts were not very immunogenic by examining stimulation indices in a 1-way mixed lymphocyte-fibroblast cell culture. However, the fact that the allogenicity of the fibroblasts was maintained after cryopreservation, even after 24 weeks, and was upregulated by addition of IFN- $\gamma$ seems to be compatible with findings reported previously. 
Because IFN- $\gamma$ is usually present during graft rejection, ${ }^{4,18}$ fibroblasts may trigger donor tissue rejection by the recipient, even though they are immunologically less potent under nonstimulated conditions than other antigen-presenting cells, such as vascular endothelial cells, airway epithelial cells, and dendritic cells. Besides upregulation of HLA-2, enhancement of expression of HLA-1 and ICAM-1, a costimulatory molecule, expressed on the cell surface of fibroblasts may contribute to stimulation of the recipient's immune system. ${ }^{10,19,20}$ Our findings appear to support other findings on the relationship between fibroblasts making up the matrix of implanted allografts and chronic rejection.

In contrast to our results suggesting persistent fibroblast immunogenicity, corneal fibroblasts and myofibroblasts have been shown to secrete a transforming growth factor ${ }^{21}$ that is an inhibitor of HLA-2 expression, ${ }^{22}$ and this may contribute to the low degree of immunogenicity of fibroblasts making up allograft tissue.

Of course, tissue allografts consist of many types of cells, and thus our findings regarding the fibroblasts present in abundance in cryopreserved allografts are considered to be only one factor in graft rejection. Other mechanisms, such as loss of potent immunogenic antigen-presenting cells during the cryopreservation and thawing procedure or modification of allogenicity expressed on the cell surface by cryopreservation, may also contribute to alterations in the allogenicity of allografts and the resulting long-term outcome.

\section{Conclusion}

Although the detailed mechanism of the long-term degeneration of transplanted cryopreserved tissue allografts is still unclear, well-preserved fibroblasts within the matrix of the allograft may contribute to this phenomenon.

We thank Mr Chikuma Hamada of the Department of Biostatistics for advice and assistance with statistical analysis.

\section{REFERENCES}

1. Mukaida T, Shimizu N, Aoe M, et al. Experimental study of tracheal allotransplantation with cryopreserved grafts. J Thorac Cardiovasc Surg 1998;116:262-6.

2. Aoki T, Yamato Y, Tsuchida M, et al. Successful tracheal transplantation using cryopreserved allografts in a rat model. Eur $\mathbf{J}$ Cardiothorac Surg 1999;16:169-73.

3. Tojo T, Niwaya K, Sawabata N, Nezu K, Kawachi K, Kitamura $\mathrm{S}$. Tracheal allogenic immunoresponse is reduced by cryopreservation: canine experiment. Transplant Proc 1996;28:1814-5.

4. Salmon RN, Friedman GB, Callow AD, Payne DD, Libby P. Cryopreserved aortic homografts contain viable smooth muscle cells capable of expressing transplantation antigens. J Thorac Cardiovasc Surg 1993;106:1173-80.
5. Vogt PR, Stallmach T, Niederhäuser U, et al. Explanted cryopreserved allografts: a morphological and immunohistochemical comparison between arterial allografts and allograft heart valves from infants and adults. Eur J Cardiothorac Surg 1999;15:639-45.

6. Messier RH Jr, Bass BL, Domkowski PW, Hopkins RA. Interstitial cellular and matrix restoration of cardiac valves after cryopreservation. J Thorac Cardiovasc Surg 1999;118:36-49.

7. Lange PL, Hopkins RA. Allograft valve banking: techniques and technology. In: Hopkins RA, editor. Cardiac reconstructions with allograft valves. New York: Springer-Verlag; 1989. p. 37-64.

8. Johnson DL, Sloan C, O'Halloran A, Yacoub MH. Effect of antibiotic pretreatment on immunogenicity of human heart valves and component cells. Ann Thorac Surg 1998;66:S221-4.

9. Nakajima J, Ono M, Kobayashi J, et al. Effect of cryopreservation on the allogenicity of an airway epithelial cell line. Transplant Proc 1998;30:3366-7.

10. Nakajima J, Ono M, Takeda M, Kawauchi M, Furuse A, Takizawa H. Role of costimulatory molecules in airway epithelial cells acting as alloantigen-presenting cells. Transplant Proc 1997;29:2297-300.

11. Saalbach A, Aust G, Haustein UF, Herrmann K, Anderegg U. The fibroblast-specific MAb AS02: a novel tool for detection and elimination of human fibroblasts. Cell Tissue Res 1997;290:593-9.

12. Kirklin JK, Smith D, Novick W, et al. Long-term function of cryopreserved aortic homografts: a ten-year study. J Thorac Cardiovasc Surg 1993;106:154-66.

13. Lupinetti FM, Tsai TT, Kneebone JM, Bove EL. Effect of cryopreservation on the presence of endothelial cells on human valve allografts. J Thorac Cardiovasc Surg 1993;106:912-7.

14. Ono M, Nakajima J, Lee MC, Takamoto S. Influence of cryopreservation on antigen expression and immunogenicity of human vascular endothelial cells. Transplant Proc 1999;31:9857.

15. Lee MC, Ono M, Nakajima J, et al. Interferon- $\gamma$-induced expression of HLA-DR and LFA-3 was enhanced by cryopreservation. Transplant Proc 1998;30:2964-5.

16. Koolbergen DR, Hazekamp MG, Kurvers M, et al. Tissue chimerism in human cryopreserved homograft valve explants demonstrated by in situ hybridization. Ann Thorac Surg 1998;66:S225-32.

17. Pedagogos E, Hewitson TD, Walker RG, Nicholis KM, Becker GJ. Myofibroblast involvement in chronic transplant rejection. Transplantation 1997;64:1192-7.

18. Bishop GA, Hall BM, Suranyi MG, Tiller DJ, Horvath JS, Duggin GG. Expression of HLA antigens on renal tubular cells in culture. Evidence that mixed lymphocyte culture supernatants and gamma interferon increase both classI and classII HLA antigens. Transplantation 1986;42:671-9.

19. Ando Y, Beck Y, Tomikawa S, Eriguchi M, Muto T, Takiguchi M. Cell-mediated graft rejection observed in two lines of human histocompatibility leukocyte antigen classI transgenic mice. Transplantation 1999;27:904-8.

20. Cunningham AC, Kirby JA. Regulation and function of adhesion molecule expression by human alveolar epithelial cells. Immunology 1995;86:279-86.

21. Masur SK, Dewal HS, Dinh TT, Erenburg I, Petridou S. Myofibroblasts differentiate from fibroblasts when plated out at low density. Proc Natl Acad Sci USA 1996;94:4219-23.

22. Glimcher LH, Kara CJ. Sequences and factors: a guide to MHC classII transcription. Annu Rev Immunol 1992;10:13-49. 